Vol. 38(1), pp. 71-82, June 2019

ISSN 1821-536X (print)

ISSN 2619-8789 (electronic)
Tanzania Journal of Engineering and Technology

Copyright (C) 2019 College of Engineering and

Technology, University of Dar es Salaam

Full Length Research Paper

\title{
Influence of Tempering and Cryogenic Treatment on Retained Austenite and Residual Stresses in Carbonitrided 18CrNiMo7-6 Low Alloy Steel
}

\author{
Richard J. Katemi ${ }^{*}$, Jérémy Epp ${ }^{2,3}$ \\ ${ }^{1}$ University of Dar es Salaam, Chemical and Mining Department, P.O. Box 35131, Dar es Salaam, \\ Tanzania \\ ${ }^{2}$ Leibniz-Institut für Werkstofforientierte - IWT Bremen, Badgasteiner str. 3, 28359 Bremen, \\ Germany \\ ${ }^{3}$ MAPEX Center for Materials and Processing, University of Bremen, Badgasteiner str. 3, 28359 \\ Bremen, Germany \\ *Corresponding author: rkatemi@udsm.ac.tz
}

\begin{abstract}
This work investigated the influence of tempering conditions coupled with cryogenic treatment on thermal stabilization of retained austenite and residual stress distributions in carbonitrided 18 CrNiMo76 low alloy steel samples. The carbonitriding conditions were set to enable attaining surface carbon and nitrogen content of 0.87 and 0.34 mass.-percent respectively. After carbonitriding, some of the samples were subjected to varying tempering conditions followed by cryogenic treatment at $-120^{\circ} \mathrm{C}$ using nitrogen gas. Analysis of both retained austenite and residual stresses was conducted using X-ray diffraction. In the as-quenched state, carbonitrided samples contained 52 mass.-percent. Samples that were directly subjected to the cryogenic treatment after quenching retained only about 20 mass.-percent of austenite. Samples subjected to variant tempering conditions coupled with cryogenic treatment retained at least 30 masses.-percent of austenite. A thermal stabilization of retained austenite which increases with increasing temperature was identified. On tempering at $240^{\circ} \mathrm{C}$ for 14 hours retained austenite becomes unstable and decomposes to bainite leading to the low initial amount of retained austenite before cryogenic treatment. It can be concluded that the tempering process coupled with cryogenic treatment leads to an increasing hardness, to higher compressive residual stresses as well as to a shift of the location of maximum compressive residual stress toward the surface.
\end{abstract}

Keywords: Carbonitriding, cryogenic, residual stress, residual stress, tempering, XRD.

\section{INTRODUCTION}

In plain carbon and low alloy steels containing more than $0.4 \%$ carbon, retained austenite (RA) remains in the microstructure in ashardened state (Larson and Shin, 1980). Several factors such as chemical composition, rate of cooling and the quenchant temperature affect the amount of retained austenite (Zhang and Findley, 2013; Takaki et al., 2004). Other investigators (Kokosza and Pacyna, 2005; Colaço and Vilar, 2004), have pointed out that residual stress state, grain size and dislocation density may influence the amount of retained austenite.

Cryogenic and/or tempering treatment are the most used post-heat treatments to reduce the level of RA in hardened steels. If the samples are immediately subjected to cryogenic treatment after quenching, more austenite present at room temperature (RT) can be further transformed to martensite due to increased undercooling below martensite start temperature (MS). In this case little or no 
autotempering effect is considered to occur (Stratton and Surberg, 2009). On the contrary, holding the samples at room temperature or at elevated temperatures for some time leads to stabilization of retained austenite which then becomes more difficult to transform to martensite during cryogenic treatment.

The stabilization is advantageous as RA in case-hardened parts. It is considered to occur by pinning mechanism (Stratton and Surberg, 2009). According to the nature and mechanisms involved, the stabilization of RA has been divided into three types, namely: thermal, mechanical and chemical stabilization (Kokosza and Pacyna, 2005). Among the three types, thermal stabilization has constantly attracted much attention (Mohanty, 1995; Podder and Bhadeshia, 2010). The thermal stabilization of retained austenite is characterized by diffusion of interstitial atoms toward the areas of high dislocation density and grain boundaries leading to inhibiting further martensitic transformation and hindrance to the growth of martensite nuclei through loss of mobility of austenite-martensite interface and strengthening of retained austenite matrix (Epp et al., 2012). Moreover, after quenching, plate martensite and retained austenite phase which are saturated with carbon/nitrogen atoms become somewhat unstable. Application of thermal energy to these phases can cause microstructural changes during which retained austenite transform to lower bainite. This effect is more prominent when the sample is tempered in the range 150 to $300^{\circ} \mathrm{C}$ (stage II tempering) for sufficient time (Parrish, 1999).

To date, nearly all the afore-mentioned investigations were conducted on carburized samples with carbon atoms in solid solution. For carbonitrided samples, however, not only carbon atoms occupy these sites but also nitrogen atoms. Nitrogen like other alloying elements such as nickel and chromium does not only stabilize retained austenite, but also enhances temper resistance. The extent of thermal stabilization is both temperature and time dependent. This in turn necessitates a thorough understanding the effect of tempering temperature and time coupled with cryogenic treatment on thermal stabilization for carbonitrided low alloy steel. The study of thermal stability of retained austenite is important because carbonitrided components when in service must remain stable to avoid distortion and pre-mature failures. In this work, the influence of tempering temperature and time on retained austenite and residual stress distributions for carbonitrided 18CrNiMo7-6 low alloy steel grade were investigated.

\section{METHODS AND MATERIALS}

\section{Material and Carbonitriding Treatment}

The material investigated in this study was the 18CrNiMo7-6 low alloy steel grade with chemical composition given in Table 1. Discshaped samples with a diameter of $34 \mathrm{~mm}$ and a thickness of $8 \mathrm{~mm}$ were prepared. The samples were then subjected to a two-stage gaseous carbonitriding process consisting of a boost and a diffusion stage. In the boost stage, the temperature, carbon potential, and ammonia enrichment rate were maintained at $940^{\circ} \mathrm{C}, 1.2$ Vol.- $\%$, and $0.5 \mathrm{l} / \mathrm{h}$, respectively. In the diffusion stage the temperature, carbon potential, and ammonia enrichment rate were maintained at $850^{\circ} \mathrm{C}, 0.94 \mathrm{Vol} .-\%$, and 0.02 $1 / \mathrm{h}$, respectively. The carbon potential $(\mathrm{Cp})$ in the carbonitriding atmosphere was controlled by controlling the voltage output of a Zirconia oxygen sensor. After carbonitriding, samples were quenched into oil held at $60^{\circ} \mathrm{C}$ followed by classifying them into three groups. Samples in the first group were analyzed in their asquenched state whereas samples in the seond group were directly subjected to cryogenic treatment. In the last group, samples were subjected to variant tempering conditions as provided in Table 2. Three tempering temperatures, 120,170 and $240^{\circ} \mathrm{C}$ were considered whereas the tempering times were 1, 2 and 14 hours. After tempering, samples were cold treated at $-120^{\circ} \mathrm{C}$ for 2 hours using nitrogen gas. 
Determination of Retained Austenite and Residual Stresses

The determination of RA and residual stress (RS) was performed using an Analytical X-ray MZ VI E (GE Inspection technology) with a Position Sensitive Detector. For the measurements, $\mathrm{Cr}-\mathrm{K} \alpha$ radiations $\left(\lambda_{\alpha 1}=2.28975\right.$ $\AA$ A) produced by a standard sealed X-Ray tube operated at $33 \mathrm{kV}$ and $40 \mathrm{~mA}$ was used. The primary beam was defined by a collimator with $2 \mathrm{~mm}$ in diameter and vanadium was used as a filter for $\mathrm{Cr}-\mathrm{K}_{\beta}$ radiations.

For RA, the scan range was from $60^{\circ}$ to $164^{\circ} 2$ with a scan step size of $0.050^{\circ} 2$ and scan speed of 0.658 steps per second. The measurements were performed at the centre of the disc samples after a successive layer removal by electro-polishing. The electropolishing was carried out using an electrolyte solution containing $80 \% \quad \mathrm{H}_{3} \mathrm{PO}_{4}$ and $20 \%$ $\mathrm{H}_{2} \mathrm{SO}_{4}$. Low current setting was used to enable a smooth surface and avoid heating of the solution and of the sample which in turn could lead to residual stress relaxation. X-ray diffraction profiles analysis was performed by the Rietveld Method (software Topas 4.2, Bruker Axs) (Young, 1993) using a fundamental parameter refinement approach. A NIST $\mathrm{LaB}_{6}$ reference powder was measured to determine the instrumental contribution on the diffraction patterns. The Rietveld refinement is based on the minimization of the difference between the observed (experimental) profile and the computed profile in which the discrepancy index, the R-weighted pattern (Rwp) is used as a measure of quality of fit. In this case, the quality of the profile fit was characterized by a low value of Rwp $\leq 2$.

Due to low peak intensity when the amount of RA falls below $20 \%$, investigation of RS distribution was performed in martensite/bainite only. The scan range of the considered $\{211\}$ peak was from $142^{\circ}$ to $164^{\circ}$ with a scan step size of $0.15^{\circ} 2$ and scan speed of 0.006 steps per second. The measurements were performed at the center of the sample in a Chi-mode with tilt angles between $-45^{\circ}$ to $+45^{\circ}$ in 11 steps. The average center of gravity method with a mean bottom threshold of 30 to $80 \%$ was used to locate the position of the stressed peak position. The Young's modulus and coefficient of Poisson for $\{211\}$ were 220 $\mathrm{GPa}$ and 0.28 (Eigenmann and Macherauch, 1996).

\section{Microstructures and Microhardness}

The micrographic acquisition was done using a light microscope. After preparation, samples were chemically etched in $3 \%$ alc. $\mathrm{HNO}_{3}$ for $40 \mathrm{sec}$. Microhardness measurement was done using a micro-indentation tester $(H M V-2$, Shimadzu) with $1000 \mathrm{p}$ load applied for 15 seconds in Vickers mode.

Table 1: Chemical composition for 18CrNiMo7-6 (DN 1.6587) steel grade determined using Optical Emission Spectroscopy (OES)

\begin{tabular}{|l|c|c|c|c|c|c|c|c|c|}
\hline Eelement & $\mathrm{C}$ & $\mathrm{Cr}$ & $\mathrm{Ni}$ & $\mathrm{Mn}$ & $\mathrm{Mo}$ & $\mathrm{Si}$ & $\mathrm{Al}$ & $\mathrm{S}$ & $\mathrm{Fe}$ \\
\hline OES analysis (mass.-\%) & 0.157 & 1.65 & 1.57 & 0.517 & 0.259 & 0.269 & 0.022 & 0.028 & bal \\
\hline
\end{tabular}


Table 2: Tempering and Cryogenic Treatment Conditions

\begin{tabular}{|c|c|c|c|}
\hline S/No & Tempering temperature $\left[{ }^{\circ} \mathbf{C}\right]$ & Tempering time $[\mathbf{h}]$ & Cryogenic treatment $\left[{ }^{\circ} \mathbf{C} / \mathbf{h}\right]$ \\
\hline 1 & As-quenched & - & \\
2 & As-quenched & - & $-120 / 2$ \\
\hline 3 & 170 & 2 & - \\
\hline 4 & 120 & 1 & $-120 / 2$ \\
\hline 5 & 120 & 2 & $-120 / 2$ \\
6 & 120 & 14 & $-120 / 2$ \\
\hline 7 & 170 & 1 & $-120 / 2$ \\
\hline 8 & 170 & 2 & $-120 / 2$ \\
\hline 9 & 170 & 14 & $-120 / 2$ \\
\hline 10 & 240 & 1 & $-120 / 2$ \\
\hline 11 & 240 & 2 & $-120 / 2$ \\
\hline 12 & 240 & 14 & $-120 / 2$ \\
\hline
\end{tabular}

\section{RESULTS AND DISCUSSION}

\section{Carbon and Nitrogen Depth Profiles}

Figure 1 presents the carbon and nitrogen depth profiles of the samples after carbonitriding treatment. The maximum concentration is 0.87 $\% \mathrm{C}$ and $0.34 \% \mathrm{~N}$ occurring at a depth of 50 $\mu \mathrm{m}$ from the surface. Analysis of the first 50 $\mu \mathrm{m}$ from the surface revealed depletion of alloying elements. Such depletion of alloying element has been observed in the scholarly work of the authors (Katemi et al., 2014a). The depletion elements are mainly attributed to inter- and/ or intra grain boundary oxidation and precipitates formation. The depletion of alloying in this range may lead to bainitic transformation during quenching thereby reducing not only the hardness but also the level of compressive residue stresses (Ingham and Clarke, 1983).

\section{Microstructures}

Typical microstructures of the case-hardened layer for carbonitrided 18CrNiMo7-6 samples for as-quenched state and after cryogenic treatment are given in Figure 2. The case microstructures are characterized by plate martensite (dark), retained austenite (white) and finely dispersed precipitates of carbides and/ or nitrides. The martensite in samples
(Figure 2a, c to e) consist of plates with large sizes while such plates could not be resolved with optical microscope for the specimen directly cold treated (Figure 2b).

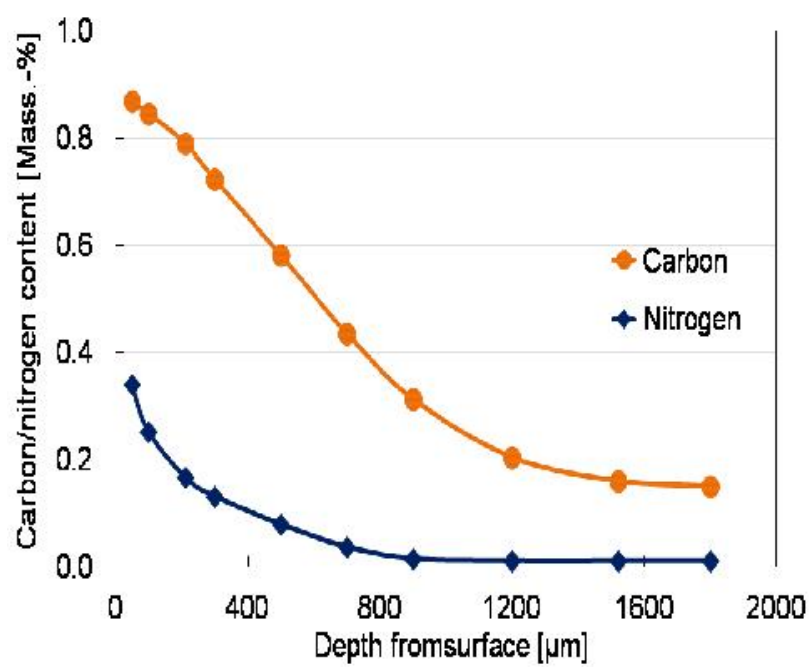

Figure 1: Carbon and nitrogen depth profiles

Darkening of martensite plates, which can be attributed to clustering of carbon and nitrogen atom, increases with increasing temperature. A considerable difference in retained austenite can be observed between Figure $2 \mathrm{e}$ and $2 \mathrm{f}$ samples which were tempered at $240^{\circ} \mathrm{C}$ for 2 and 14 hours, respectively. Furthermore, microstructures are characterized by subsurface inter- and/ or intra grain boundary oxidation which is normal for carbonitriding/carburizinng treatments carried out in endothermic 
atmospheres (Sastry et al., 1982). The internal oxidation and alloy depletion affect the transformation behavior principally by increasing the martensite start temperature leading to high-temperature transformation products such as pearlite and both lower and
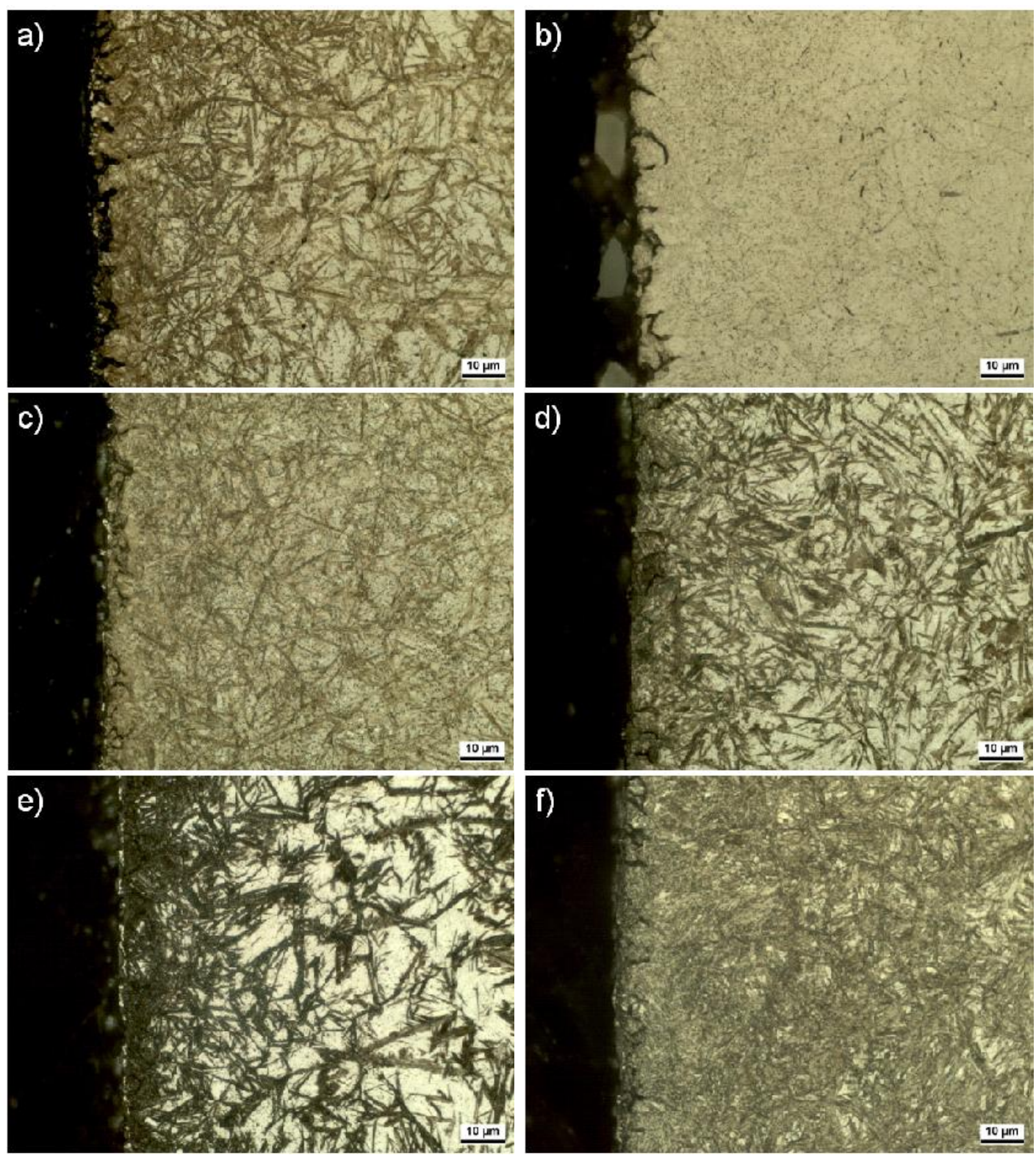

Figure 2: Typical case microstructures after isothermal holding followed by cold treatment: a) As-quenched, b) directly cold treated after quenching, c) tempered at $120^{\circ} \mathrm{C}$ for 2 hours + CT, d) tempered at $170^{\circ} \mathrm{C}$ for 2 hours $+\mathrm{CT}$, e) tempered at $24^{\circ} \mathrm{C}$ for 2 hours $+\mathrm{CT}$, f) tempered at $240{ }^{\circ} \mathrm{C}$ for 14 hours $+\mathrm{CT}:(C T-C r y o g e n i c$ Treatment $)$

\section{Microhardness Distribution}

Figure 3 illustrates the micro-hardness distributions for as-quenched sample and after upper bainite. Similar subsurface grain boundary oxidation problems have been observed (Bischoff et al., 2010; Okhi, 2006) and it has been attributed to preferential oxidation of alloying elements. 
hardness value $(600 \mathrm{HV})$ is observed in the asquenched specimen with its maximum hardness of about $780 \mathrm{HV}$ occurring at a depth of $400 \mu \mathrm{m}$ from the surface (Figure 3a). The low hardness in the surface is mainly due to the presence of high amount ( $\approx 0$ mass.- $\%$ ) soft retained austenite phase. The direct cryogenically treatment sample (Figure 3b) experienced the highest hardness value of about $900 \mathrm{HV}$ mainly due to additional transformation of retained austenite to martensite phase. This in turn enhances dimensional stability because less austenite is available to transform to martensite by stress or strain-controlled mechanisms (Davis, 2002). Comparing Figures $3 \mathrm{c}$, d, and e, the maximum hardness value decreases with increasing tempering temperature. The maximum hardness values are about $900 \mathrm{HV}, 850 \mathrm{HV}$, and $740 \mathrm{HV}$ on tempering at $120^{\circ} \mathrm{C}, 170^{\circ} \mathrm{C}$ and $240^{\circ} \mathrm{C}$, respectively. This is mainly due to the fact that thermal stabilization of retained austenite increases with tempering temperature; consequently, the amount of retained austenite transformed during cryogenic treatment decreases. Obviously, holding the sample at $240^{\circ} \mathrm{C}$ for 14 hours (Figure 3f) leads to decomposition of retained austenite to bainite during tempering. On the other hand, the core hardness seems to be less affected by the tempering conditions as well as the cryogenic treatment and remains relatively at about 450 $\mathrm{HV}$ because much carbides/nitrides precipitations may have taken place by autotempering.

\section{Retained Austenite Distribution}

The retained austenite depth profiles for the asquenched and directly cold treated samples are given in Figure 4. As can be observed from the figure, the as-quenched sample retained a maximum of 54 mass.- $\%$ austenite which occurs at a depth of $50 \mu \mathrm{m}$ from the surface whereas the directly cold treated sample, in which the transformation of retained austenite into martensite is further continued, retains only 23 mass.-\%. In this case, both martensite and RA phase may contain equal amount of carbon and nitrogen in solid solution. The results in this figure set a basis for determining the influence of tempering conditions on the thermal stabilization of RA. In this context, if the austenite in the sample is $100 \%$ thermally stabilized would retain as much as 54 mass.- $\%$ of austenite after cryogenic treatment. 

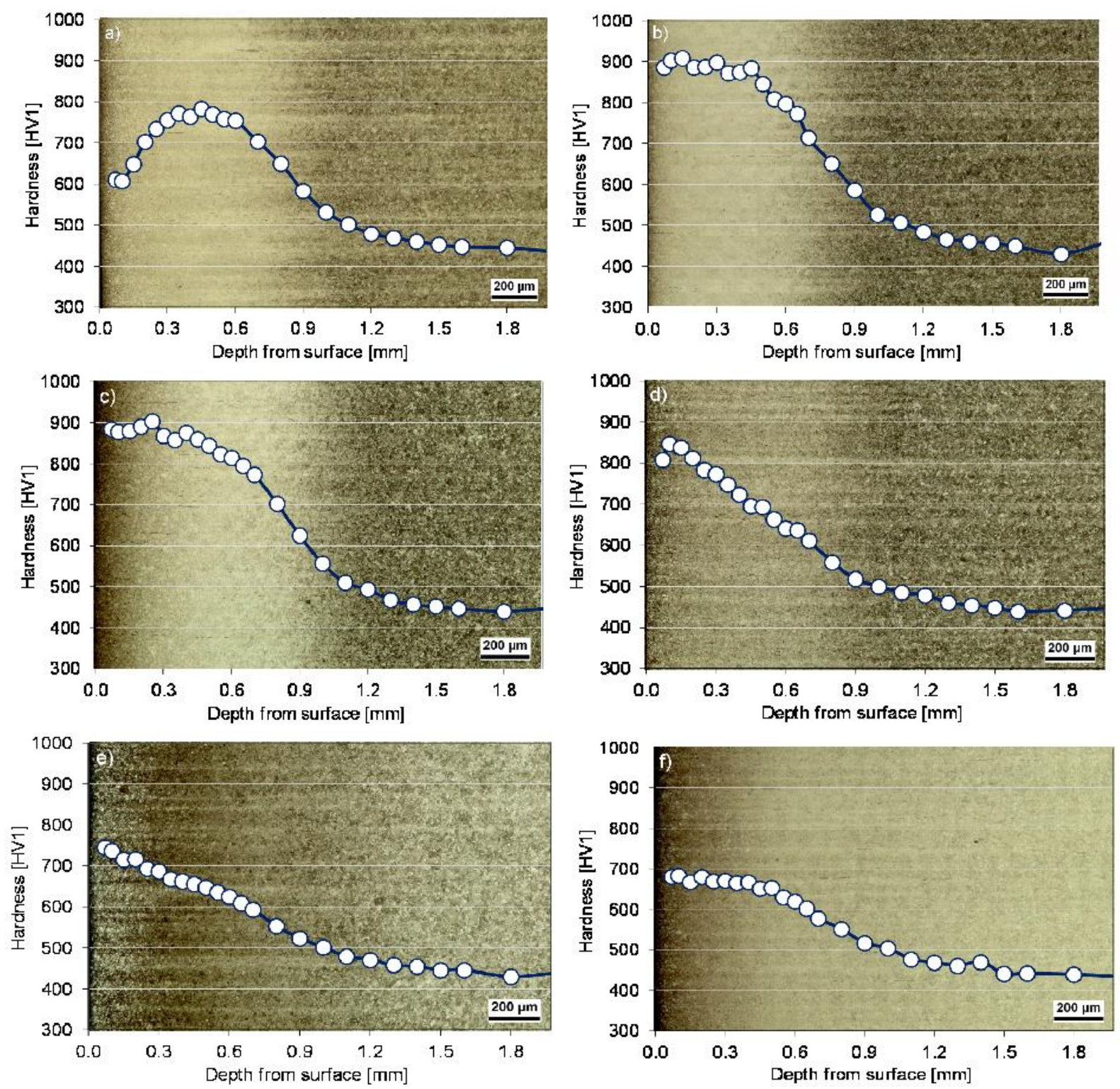

Figure 3: Microhardness distributions imbeded on their respective micrographs : a) Asquenched b) Direct CT; c) tempered at $120^{\circ} \mathrm{C}$ for 2 hours + CT; d) tempered at $170^{\circ} \mathrm{C}$ for 2 hours + CT; e) tempered at $240^{\circ} \mathrm{C}$ for 2 hours + CT; f) tempered at $240^{\circ} \mathrm{C}$ for 14 hours $+\mathrm{CT}$

Figure 5 presents the RA depth profiles after cryogenic treatment at $-120{ }^{\circ} \mathrm{C}$ for 2 hours. Prior to cryogenic treatment, samples were subjected to different tempering cycles. The amount of retained austenite decreases considerably (about 30 mass. $-\%$ at a depth of $50 \mu \mathrm{m})$ in comparison to that retained in the asquenched state. However, the amount of retained austenite after tempering followed by cryogenic treatment remains substantially greater in comparison to that retained in the sample which was direct cryogenically treated
(Figure 4). This behavior points out that the tempering performed before cryogenic treatment leads to stabilization of retained austenite. It can be seen from Figure $5 \mathrm{a}$ and $\mathrm{b}$ that samples tempered for 1 and 2 hours, the RA considerably increases with increasing tempering temperature. The increase in RA is mainly attributed to thermally activated chemical stabilization of RA rendering more difficult to transform into martensite during cryogenic treatment at $-120^{\circ} \mathrm{C}$. 


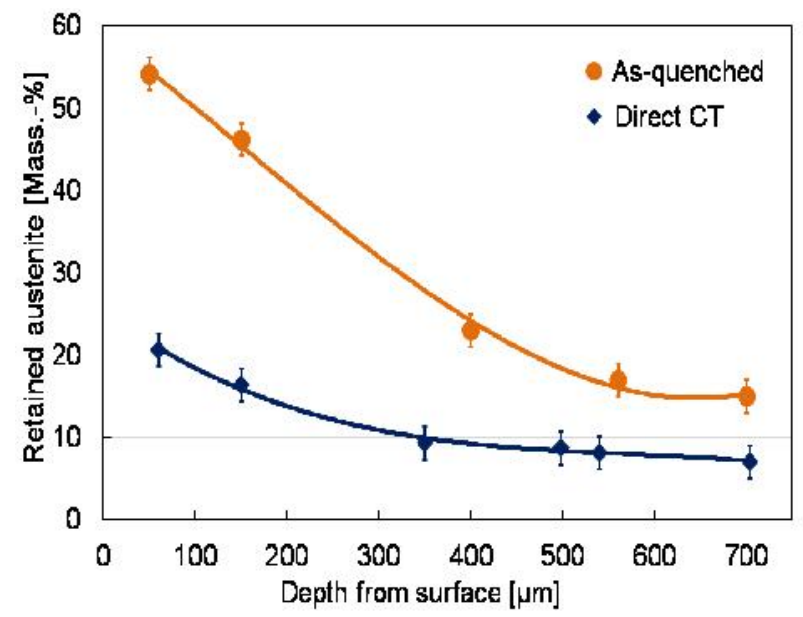

Figure 4: Retained austenite depth profiles for as-quenched and directly cold treated samples.

The stabilization effect is linked to the segregation of interstitial atoms toward the areas of high dislocation density and grain boundaries leading to impediment to further nucleation of martensite phase and hindrance to the growth of martensite nuclei through: i) the loss of mobility of austenite-martensite interface and ii) the strengthening of residual austenite matrix (Mohanty, 1995). Moreover, carbon and nitrogen enrichment in austenite might take place during tempering leading to a chemical stabilization effect. In addition, nickel influence considerably the stabilization of austenite; consequently retained austenite in 18CrNiMo7-6 steel, which contains about 1.57 mass.-\% nickel will have high tendency to stabilize (Stratton and Surberg, 2009).

On the contrary, the sample tempered at $240^{\circ} \mathrm{C}$ for 14 hours (Figure 5c) exhibits a different tendency in which less austenite is retained in comparison to the samples tempered 120 and $170{ }^{\circ} \mathrm{C}$ for 14 hours. This is thought that besides other micro-structural changes such as precipitation of " $-\mathrm{Fe}_{16}(\mathrm{C}, \mathrm{N})_{2}$ carbonitrides (Cheng et al., 1992) that may take place during isothermal holding at $240^{\circ} \mathrm{C}$ for 14 hours, RA decomposes to lower bainite leading to reduced initial retained austenite before cryogenic treatment. This in turn prompt further in-situ investigation on microstructure as well as residual stress evolution.

\section{Residual Stress Distributions}

The residual stress (RS) depth profiles for asquenched, tempered, and directly cold treated samples are shown in Figure 6. As can be seen, although in all samples residual stresses exhibit similar residual stress distributions, the magnitudes of RS are greatly different. The similarity of RS distributions arises from the fact that, all specimens are characterized by less compressive in the first $200 \mu \mathrm{m}$ from the surface, compressive RS peaks within the case, and a decrease in compressive RS toward the case/core interface. The compressive RS peaks are $-470 \mathrm{MPa}$ at a depth of $700 \mu \mathrm{m}$ for asquenched, $-240 \mathrm{MPa}$ at a depth of $850 \mu \mathrm{m}$ for the sample tempered at $170^{\circ} \mathrm{C}$ for 2 hours, and $-530 \mathrm{MPa}$ at a depth of $560 \mu \mathrm{m}$ directly cryogenically treated sample.

Considering the RS values in the as-quenched sample as the basis for comparison, tempering at $170{ }^{\circ} \mathrm{C}$ for 2 hours relaxes considerably the compressive RS at each point and shifts the location of compressive RS peak toward the case/core interface. A relaxation of up to about $-240 \mathrm{MPa}$ is observed. Such relaxation is attributed to annihilation of thermally activated dislocations accompanied by the movement of carbon and nitrogen interstitial atoms toward the area of high dislocation density and grain boundaries (Epp et al., 2012; Mohanty, 1995). On the other hand, the immediate cryogenic treatment enhances the magnitudes of compressive RS and shifts the location of compressive RS peak toward the surface. An increase of up to $-200 \mathrm{MPa}$ occurred. The increased magnitude of compressive $\mathrm{RS}$ is linked to continued transformation of retained austenite to martensite during cryogenic treatment at $-120{ }^{\circ} \mathrm{C}$ for 2 hours leading to additional volume expansion in the case. 

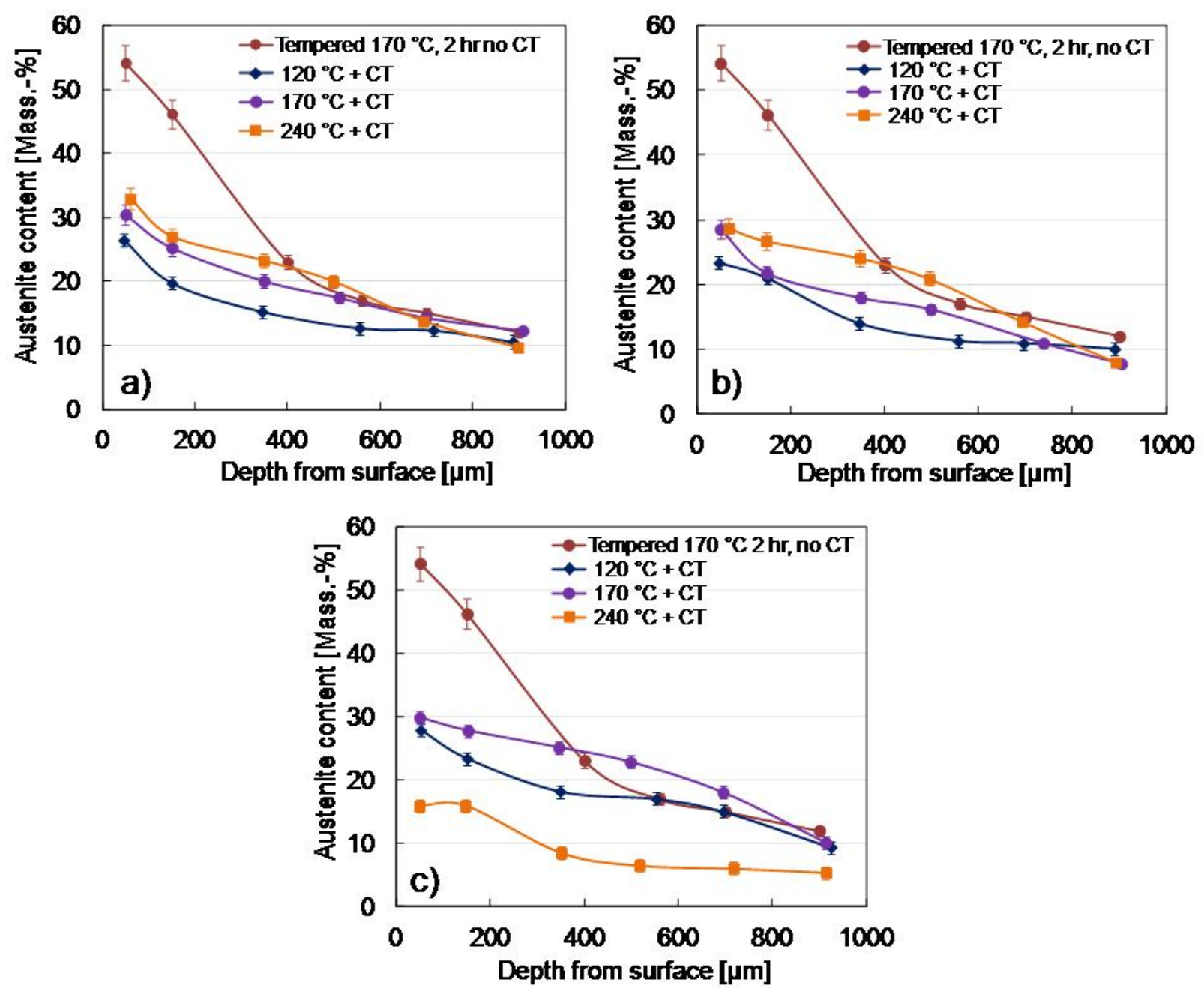

Figure 5: Retained austenite depth profiles: a) tempered at different temperatures for 1 hour $+\mathrm{CT}$; b) tempered at different temperatures for 2 hours + CT; c) tempered at different temperatures for 14 hours + CT Regular

Figure 7 gives the RS distributions for samples tempered at different tempering conditions followed by cryogenic treatment at $-120{ }^{\circ} \mathrm{C}$ for 2 hours. In general, tempering followed by cryogenic treatment enhances significantly and the distribution of compressive RS. In the first $500 \mu \mathrm{m}$, compressive RS of up to about -450 $\mathrm{MPa}$ are reached at a depth of $50 \mu \mathrm{m}$ whereas beyond $500 \mu \mathrm{m}$ such stresses are slightly relaxed. In the first $500 \mu \mathrm{m}$, the increase in compressive $\mathrm{RS}$ is mainly due to additional transformation of additional retained austenite to martensite during cryogenic treatment. The new formed martensite leads to volume expansion that would be constrained and compressive RS would be increased (Chongkim et al., 1981).

As expected, compressive RS decrease with increasing tempering temperature (Figure 6a and b). Such decrease is associated to the increased thermal stability of RA as a result less RA is transformed to martensite during cryogenic treatment. On the contrary, sample tempered at $240^{\circ} \mathrm{C}$ for 14 hours experienced less compressive $\mathrm{RS}$ of about $-200 \mathrm{MPa}$ at a depth of $50 \mu \mathrm{m}$. Tempering at $240^{\circ} \mathrm{C}$ for 14 hours leads to decomposition of RA to lower point; consequently, less amounts of RA are available during cryogenic treatment. 


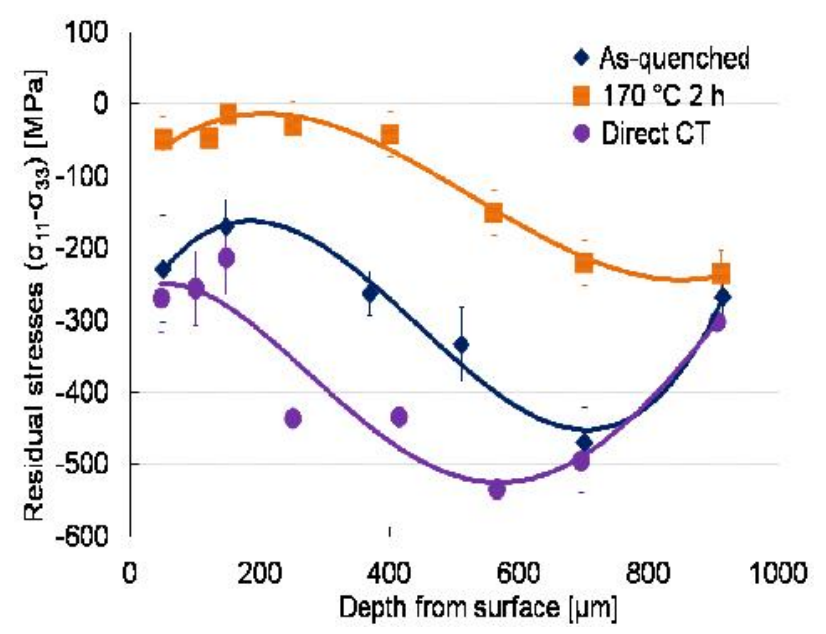

Figure 6: Residual stress depth profiles for as-quenched, tempered and directly cold treated specimens
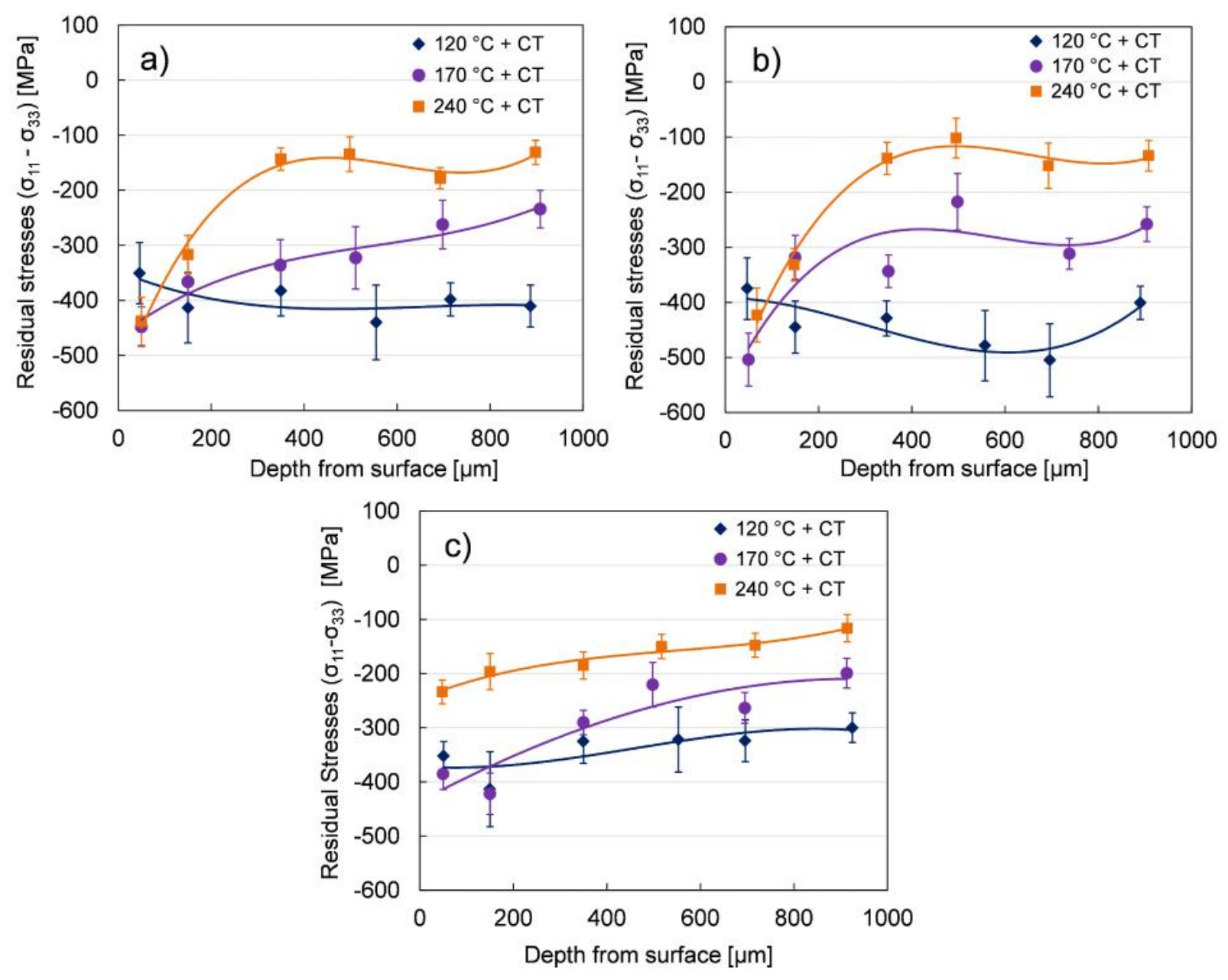

Figure 7: Residual stress distributions: a) tempered for $1 \mathrm{~h}+\mathrm{CT}$, b) tempered for $2 \mathrm{~h}+\mathrm{CT}$; c) tempered for $14 \mathrm{~h}+\mathrm{CT}$

Despite the cryogenic treatment, in particular for samples tempered at $170^{\circ} \mathrm{C}$ and $240^{\circ} \mathrm{C}$, beyond $500 \mu \mathrm{m}$ the samples experienced less compressive RS in comparison to the asquenched sample (Figure 6). It can be seen in Figure 5 that beyond $500 \mu \mathrm{m}$ less than 20 mass.- $\%$ of austenite is retained and negligible proportion of it would be expected to transform to new martensite during cryogenic treatment, which in turn could enhance compressive RS. Therefore, in this case, the decrease in compressive RS is largely attributed to thermal relaxation. 
Although the RS in RA after cryogenic treatment were not experimentally determined due low intensity of RA when it is below 20 mass.-\%, it has been suggested that any austenite surviving this treatment would be in tensile state. Such tensile stresses in RA were observed in the work of Kim (1983) where RS in both martensite and retained austenite in EX55 steel grade after subzero treatment were determined. While the sub-zero treatment in this work improved significantly the compressive RS in martensite phase, in his work the sub-zero treatment did not induce significant compressive RS in the first $500 \mu \mathrm{m}$. Due to the nature of the RS distribution, one can speculate that in his work after quenching samples were not held at elevated temperature rather than immediately sub-zero treated at $80^{\circ} \mathrm{C}$ for 4 hours.

It is obvious that cryogenic treatment raises the hardness in the case that would be expected to have a positive influence on the resistance to wear. Moreover, it induces compressive RS which are essential to improving bending fatigue strength. By contrast, the residual stresses in any austenite surviving cryogenic treatment would likely be less compressive and/ or in tensile state. The low compressive and/ or tensile state in RA have been reported in the earlier work of the authors (Katemi et al., $2014 b$ ) in which RS in both retained austenite and martensite were measured. Okhi (2006) reports that such tensile stress in RA reduces the fatigue strength of the component. This is due the fact that the resistance of retained austenite to fatigue cracking is determined by the amount of applied energy it absorbs and uses on the formation of new martensite.

\section{CONCLUSIONS}

This work investigated the influence of tempering conditions coupled with cryogenic treatment on the stabilization of retained austenite and evolution of residual stresses for carbonitrided 18CrNiMo7-6 low alloy steel samples. The cold treatment at $-120^{\circ} \mathrm{C}$ for 2 hours was sufficient to induce the transformation of a large amount of retained austenite to martensite after any tempering cycle. If after quenching the sample is immediately subjected to cryogenic treatment about 20 mass.- $\%$ of the austenite that is retained after cryogenic treatment. Samples subjected to tempering coupled with cryogenic treatment retained about 30 mass. $-\%$ austenite and increases with increasing temperature. In other terms thermal stabilization of retained austenite increases with increasing temperature. Tempering at $240{ }^{\circ} \mathrm{C} \quad 14$ hours leads to a decomposition of retained austenite into lower bainite; consequently, reducing the initial amount of retained austenite prior to cryogenic treatment. The new martensite formed during cryogenic treatment enhances the hardness, compressive RS as well as shifting the location of maximum compressive RS towards the surface. In-situ investigation is recommended to established the rate of retained austenite decomposition as well as the evolution of residual stresses in carbonitrided parts.

\section{REFERENCES}

Bischoff S., Klümper-Westkamp H., Hoffmann F. and Zoch H.W. (2010). Development of a sensor system for gas carbonitriding- Part 1. Journal Heat Treatm. Mat., 65(3): 141-148.

Cheng L. Böttger A, and Mittemeijer E. M (1992). Tempering of iron-carbon-nitrogen martensites. Metallurgical Transaction A, 23A: 1129-1145.

Chongmin K., Diesburg, D. E. and Buck R.M. (1981). Influence of sub-zero and shotpeening treatments on impact and fatigue fracture properties of case-hardened steels. Journal Heat Treating, 2: 43-53. DOI: $10.1007 / \mathrm{BF} 02833073$

Colaço R. and Vilar R. (2004). Stabilisation of retained austenite in laser surface melted tool steels. Materials Science and Engineering A, 385: 123-127. https://doi.org/10.1016/j.msea.2004.06.069

Davis J.R. (Ed). (2002). Surface Hardening of Steel: Understanding the Basics, ASM International. ISBN: 978-0-87170-764-2 
Eigenmann B. and Macherauch E. (1996). Wontgenographische Untersuchung von Spannungszustanden in Werkstoffen. Mat.wiss. u. Werkstofftech. Part 111: 27 426437.

Epp J., Hirsch T. and Curfs C. (2012). In situ $\mathrm{X}$-ray diffraction analysis of unexpected carbon partitioning during quenching of low carbon steel. Metallurgical and Materials Transactions A, 43A: 2210-2217.

Ingham D.W. and Clarke P.C. (1983). Carburise Case Hardening - Computer Prediction of Structure and Hardness Distribution, Heat Treat. Met., 4: 91-98.

Katemi R.J., Epp J., Hoffmann F. and Steinbacher M. (2014a). Characterization of Carbonitrided 18CrNiMo7-6 Steel. Proc. 3rd Int. Conf. on Mechanical and Industrial Engineering MIE'2014: 170-175.

Katemi R.J., Epp J., Hoffmann F. and Steinbacher M. (2014b). Investigations of Residual Stress Distributions in Retained Austenite and Martensite after Carbonitriding of a Low Alloy Steel. Advanced Materials Research, 996: 550555.

https://doi.org/10.4028/www.scientific.net/ AMR.996.550

Kim C. (1983). Fracture of Case-Hardened Steels and Residual Stress Effect in CaseHardened Steels: Microstructural and Residual Stress Effects.

Kokosza A. and Pacyna J. (2005). Evaluation of retained austenite stability in heat treated cold work tool steel. Journal of Materials Processing Technology, 162-163: 327-331. https://doi.org/10.1016/j.jmatprotec.2005.02 .068

Larson J.A. and Shin S.W. (1980). Retained austenite and its measurement by X-ray diffraction. SP-453, SAE.
Mohanty O.N. (1995). On the stabilization of retained austenite: mechanism and kinetics. Material Science and Engineering B32: 267278. https://doi.org/10.1016/09215107(95)03017-4

Okhi C. (2006). Atmospheric Control Method for JIS-SUJ2 Carbonitriding Processes. NTN Technical Review No. 74.

Parrish G. (1999). Carburizing: Microstructures and Properties, ASM International. ISBN: 978-0-87170-666-9

Podder A.S. and Bhadeshia H.K.D.H. (2010). Thermal stability of austenite retained in bainitic steels. Materials Science and Engineering A, 527(7-8): 2121-2128. https://doi.org/10.1016/j.msea.2009.11.063

Sastry C.N., Khan K.H. and Wood W.E. (1982). Mechanical Stability of Retained Austenite in Quenched and Tempered AISI 4340 Steel. Metallurgical Transactions A, 13A: 676-680. https://doi.org/10.1007/BF02644435

Stratton P. and Surberg C.H. (2009). Retained austenite stabilization. Heat Treating Progress. 9(2): 25-27.

Takaki S., Fukunaga K., Syarif J. and Tsuchiyama T. (2004). Effect of Grain refinement on Thermal Stability of Metastable Austenitic Steel. Material Transactions, 45(7): 2245-2251.

Young R.A. (1993). The Rietveld Method, International Union of. Crystallography (IUCr) Book Series, Oxford University Press.

Zhang S. and Findley K.O. (2013). Quantitative assessment of the effects of microstructure on the stability of retained austenite in TRIP steels. Acta Materialia, 61: 1895-1903. https://doi.org/10.1016/j.actamat.2012.12.01 $\underline{0}$ 